DOI: $10.12737 /$ article_5c9201723dbb21.63764253

УДК $630 * 96$

ИССЛЕДОВАНИЕ СИСТЕМЫ НОРМИРОВАНИЯ В ЛЕСНОМ ХОЗЯЙСТВЕ РОССИИ

доктор экономических наук, профессор С.С. Морковина ${ }^{1}$

кандидат экономических наук Е.А. Панявина ${ }^{1}$

кандидат сельскохозяйственных наук И.А. Авдеева ${ }^{1}$

1 - ФГБОУ ВО «Воронежский государственный лесотехнический университет

имени Г.Ф. Морозова», г. Воронеж, Российская Федерация

Лесной кодекс Российской Федерации определил разделение функций государственного управления и лесохозяйственной деятельности. Государственные функции управления лесами на уровне субъекта осуществляются уполномоченным органом исполнительной власти субъекта Российской Федерации. Работы по охране, защите и воспроизводству лесов на участках, не переданных в аренду, осуществляют государственные организации различных организационно-правовых форм, на участках, переданных в аренду - предпринимательские структуры. На реализацию функций управления лесами и финансирование лесохозяйственных работ на землях, не переданных в аренду, предусмотрены субвенции из государственного бюджета и бюджетов субъектов РФ. В основе выделения субвенций на лесоуправление и ведение лесного хозяйства лежат действующие в лесном хозяйстве нормативы и методики определения норм. Установлено, что нормы выработки и нормы времени практически на все виды лесохозяйственных работ являются устаревшими. Особенно остро эта проблема стоит в лесном хозяйстве южных регионов страны, леса которых произрастают преимущественно в гористой местности. Ввиду отсутствия действующих норм времени и норм выработки по видам лесохозяйственных работ, разработаны нормы выработки и нормы времени, включая методические рекомендации по применению норм для целей разработки нормативов по видам лесохозяйственных работ, осуществляемых в горных условиях. При разработке норм выработки и норм времени применяли метод непосредственных замеров, при котором основными видами наблюдений являются фотография рабочего времени и хронометраж трудовых процессов. Представлены фрагменты разработанных норм выработки и норм времени в горных условиях на лесохозяйственные работы - прокладку минерализованной полосы. Определено, что в связи со спецификой лесного хозяйства необходима разработка типовых норм выработки и норм времени с учетом научно-исследовательских разработок, современных технологий работ и новейшей техники на регионально-типологической основе.

Ключевые слова:лесное хозяйство России, нормирование, система нормирования, нормы времени, нормы выработки.

\title{
STUDY OF THE SYSTEM OF RATIONING IN FORESTRY OF RUSSIA
}

\author{
DSc (Economics) S.S. Morkovina ${ }^{1}$ \\ $\mathrm{PhD}$ (Economics) E.A. Panyavina ${ }^{1}$ \\ $\mathrm{PhD}$ (Agriculture) I.A. Avdeeva ${ }^{1}$ \\ 1 - Federal State Budget Education Institution of Higher Education «Voronezh State University of \\ Forestry and Technologies named after G.F. Morozov», Voronezh, Russian Federation
}

\begin{abstract}
The Forest Code of the Russian Federation has defined the separation of the functions of government and forestry activities. State functions of forest management at the level of a subject are performed by an authorized executive body of a constituent entity of the Russian Federation. Work on the protection, preservation and reproduction of forests in areas not leased, carried out by the state organizations of various organizational and legal forms, in areas leased business structures. Subventions from the state budget and the budgets of the subjects of the Russian Federation are provided for the implementation of the functions of forest management and financing of forestry work on land not
\end{abstract}


leased. The basis for the allocation of subventions for forest management and forest management are the standards and methods for determining standards that are in force in forestry. It has been established that the development rates and time standards for almost all types of forestry work are obsolete. This problem is particularly acute in the forestry of the southern regions of the country, whose forests grow mainly in mountainous terrain. Due to the absence of current time standards and production standards for types of forestry work, development standards and time standards have been developed, including guidelines for the application of standards for the purpose of developing standards for types of forestry work carried out in mountainous conditions. In the development of standards and time standards used the method of direct measurements, in which the main types of observations are photographs of working time and timing of labor processes. Fragments of the developed norms of development and standards of time in mountain conditions for forestry works - laying of the mineralized strip are presented. It was determined that in connection with the specifics of forestry, it is necessary to develop standard production standards and time standards taking into account research and development, modern work technologies and the latest technology on a regional-typological basis.

Keywords:Russian forestry, rationing, rationing system, time norms, production standards.

Леса Российской Федерации составляют более четверти мировых запасов древесной массы и выполняют важные средозащитные и средообразующие функции: рекреации, туризма, охоты, водоохранные и почвозащитные, заготовки живицы, пищевых лесных ресурсов и сбора лекарственных растений, являясь не только экологическим каркасом для всей нашей планеты, но и колоссальным ресурсом для повышения благосостояния и укрепления здоровья граждан России [1].

Помимо экологической составляющей важна и экономическая составляющая потенциала лесов России, таккак он обеспечивает удовлетворение потребностипромышленности, строительства, сельского хозяйства, полиграфии, торговли, медицины в сырьевых ресурсах [2].

В основе управления лесами лежит многократно реформируемое лесное законодательство.

Введенный в действие Лесной кодекс (2006) обеспечил разделение функций государственного управления и лесохозяйственной деятельности и децентрализовал лесоуправление, передав функции распоряжения и государственного надзора за лесным фондом органам государственной власти субъектов Российской Федерации.

В настоящий момент государственные функции управления лесами на уровне субъекта осуществляются уполномоченным органом исполнительной власти субъекта Российской Федерации, на реализацию которых предусмотрены субвенции из федерального бюджета [3].

Для выполнения наработ по охране, защите и воспроизводству лесов на участках, не переданных в аренду, в созданной структуре управления лесами созданы и действуют государственные организации различных организационно-правовых форм [4].

На участках лесного фонда, переданных в аренду, хозяйственные функции (работы по восстановлению, уходу, охране и защите леса) осуществляют предпринимательские структуры в объемах и в сроки, указанные в проекте освоения лесов и договоре аренды [5]. Источниками финансирования этих работ являются средства арендаторов лесных участков.

Финансирование лесохозяйственных работ на землях лесного фонда, не переданных в аренду, осуществляется из государственного бюджета и бюджетов субъектов РФ [6].

В основе выделения субвенций на лесоуправление и ведение лесного хозяйства лежат действующие в лесном хозяйстве нормативы и методики определения норм.

В международной практике используются четыре основных типа нормативов: базовые, идеальные, достижимые, текущие.

Базовые нормативы относятся к долговременным и служат индикаторами долговременных тенденций состава затрат соответствующей им технологии производства. Идеальные нормативы могут использоваться в идеальных условиях организации производства, и мало применимы в практике. Достижимые нормативы - это тот уровень нормативов, который в наибольшей степени соответствует практической реализации.

Текущие нормативы представляют собой временно действующие нормативы, которые дейст- 
вуют в ситуациях, когда обычные достижимые нормативы не могут быть реализованы в силу отклонений в ходе производственного процесса.

Особенности нормирования в лесном хозяйстве связаны в первую очередь с разделением функций управления и хозяйствования на уровне региональных систем.

Отметим, что распределение субвенций из федерального бюджета субъектам РФ для осуществления полномочий по управлению лесами осуществляется на основании Постановления Правительства РФ от 29.12.2006 г. № 838 (ред. от 13.02.2019 г.) «Об утверждении Методики распределения между субъектами Российской Федерации субвенций из федерального бюджета для осуществления отдельных полномочий Российской Федерации в области лесных отношений, реализация которых передана органам государственной власти субъектов Российской Федерации» [7]. Порядок расчета нормативных затрат установлен на федеральном уровне Приказом Рослесхоза от 02.03.2017 № 81 «Об утверждении Порядка определения нормативных затрат на выполнение работ федеральными бюджетными и автономными учреждениями, в отношении которых Федеральное агентство лесного хозяйства осуществляет функции и полномочия учредителя» [8]. В каждом субъекте Российской Федерации приняты свои аналогичные нормативные акты, суть которых идентична.

Финансирование ведения лесного хозяйства также осуществляется с учетом производственных норм и нормативов.

Отметим, что значительная часть типовых норм времени, используемых для расчета нормативов затрат разработана в конце XX века и продолжает использоваться в экономике лесного хозяйства. Стремительное развитие отраслей народного хозяйства привело не только к замене машин и орудий, но и существенному развитию технологий.

Лесное хозяйство страны в этом плане не является исключением, и на смену трудоемким и ресурсоемким технологиям пришли новые, обеспечившие рост производительности труда. Цифровизация и интенсификация производственных процессов в лесном хозяйстве предопределили необходимость пересмотра действующих норм времени и норм выработки на лесохозяйственные работы и разработки нормативных и методических документов, позволяющих модернизировать действующие нормативы.

Изменения, произошедшие в этом плане за последние десять лет, можно оценить как незначительные.

Современное состояние нормирования труда в лесном хозяйстве характеризуется отсутствием централизованного контроля за разработкой и выполнением норм затрат труда, новые нормативные материалы не разрабатываются, нормы выработки и нормы времени практически на все виды лесохозяйственных работ являются устаревшими [9].

Особенно остро эта проблема стоит в лесном хозяйстве южных регионов страны, леса которых произрастают преимущественно в гористой местности. К горным лесам относятся все леса (в том числе заросли кедрового стланика, карликовой березы и т.п.), расположенные в пределах горных систем и отдельных горных массивов с колебаниями относительных высот местности более 100 м.

Ввиду отсутствия действующих норм времени и норм выработки по видам лесохозяйственных работ нами разработаны нормы выработки и нормы времени, включая методические рекомендации по применению норм для целей разработки нормативов по видим лесохозяйственных работ осуществляемых в горных условиях.

Норма времени - это величина затрат рабочего времени, установленная для выполнения единицы работы работником или группой работников (в частности, бригадой) соответствующей квалификации в определенных организационно-технических условиях [10].

Норма выработки - это установленный объем работы (количество единиц продукции), который работник или группа работников (в частности, бригада) соответствующей квалификации обязаны выполнить (изготовить, перевезти и т.д.) в единицу рабочего времени в определенных организационно-технических условиях [10].

Известно, что нормы времени и нормы выработки разрабатываются на те лесохозяйственные работы, которые: 
- не отражены в справочниках типовых норм времени и норм выработки лесохозяйственных работ;

- на лесохозяйственных операциях применяется техника, отличная от техники, указанной в справочниках типовых норм времени и норм выработки лесохозяйственных работ;

- нормообразующие факторы на лесохозяйственных операциях отличаются от указанных в справочниках типовых норм времени и норм выработки лесохозяйственных работ.

Считаем, что при разработке норм выработки и норм времени в лесном хозяйстве необходимо применять метод непосредственных замеров, при котором основными видами наблюдений являются: фотография рабочего времени и хронометраж трудовых процессов.

Нормы выработки и нормы времени в горных условиях разработаны на лесохозяйственные работы - прокладка минерализованной полосы.

В основу разработки норм положены:

-фотохронометражные наблюдения;

-технические характеристики орудий и инструментов, применяемых для работ;

-результаты анализа организации труда и мероприятия по её совершенствованию.

Нормы определены по исполнителям в расчете на рабочую смену продолжительностью 8 часов.

Нормами выработки учтено и отдельно не оплачивается время, затрачиваемое исполнителями работ на:

-подготовку рабочего места перед началом работы и приведение его в порядок в конце смены;

-получение задания и инструктажа на выполнение работы;

-ежесменный технический уход за инструментом;

-сдачу выполненной работы;

-отдых и личные потребности.

В описании содержания работ перечислены характерные элементы операции. Элементы, являющиеся неотъемлемой частью данной производственной операции и не приведенные в описании содержания работы, особой оплате не подлежат.
В нормах предусматривается выполнение всех работ в соответствии с действующими инструкциями и правилами по охране труда и противопожарной технике.

Нормы установлены с учётом выполнения:

-действующих нормативных документов по лесному хозяйству;

-полного оснащения рабочих мест необходимым инструментом;

-применения наиболее рациональных технологических процессов (ступенчатое точечное зажигание лесных горючих материалов);

-выполнение работ рабочими соответствующей квалификации.

Наименование профессий, разряды работ и рабочих в настоящих нормах выработки указаны в соответствии со «Справочником по тарификации механизированных и ручных работ в сельском, водном и лесном хозяйстве», утвержденным Постановлением Государственного комитета СССР по труду и социальным вопросам от 03.11. 1986 № 462/26-62 [11].

Расчеты норм времени и норм выработки на прокладку минерализованной полосы в два прохода при крутизне склона до 20 град. включает этапы:

1. Проведение фотографии рабочего времени, т.е. изучения рабочего времени путем наблюдения и измерения всех без исключения затрат на протяжении рабочего дня. Фотография проводится в целях выявления фактических показателей использования рабочего времени, причин невыполнения действующих норм, сокращения потерь времени [12].

Наблюдение проводится минимум в течение трех дней и состоит в последовательной и подробной записи в наблюдательном листе всего происходящего на рабочем месте. Результаты наблюдения за один день представлены в табл. 1. Материалы фотографии рабочего времени, полученные при наблюдении, обрабатывали, а результаты анализировали. Для этого составлялась сводка одноименных затрат рабочего времени (табл. 2). При этом суммировались все затраты рабочего времени на выполнение данного элемента рабочего процесса, отмеченные в наблюдательном листе одним и тем же номером. Суммируя затраты рабочего вре- 
мени по всем элементам, получали общую продолжительность рабочего времени.

После окончания первичной обработки фотографии рабочего времени сводные данные всех наблюдательных листов, кроме обеденного перерыва, вносили в нормировочную карту (сводную таблицу). На основе этих данных определяли фактический и проектируемый баланс времени рабочего дня (табл. 3).

Из сводки затрат рабочего времени по каждому дню наблюдений в гр. 2-4 табл. 3 заносили данные о затратах рабочего времени по элементам. Элементы рабочей смены в графе 1 распределяли в соответствии с классификацией затрат рабочего времени.

Фактическое время рабочего дня определяется сначала суммарно (гр. 5), а затем в среднем для одного дня наблюдений (гр. 6).

Фактический баланс рабочего времени подлежит анализу. При этом вскрываются резервы рабочего времени, потери рабочего времени и их причины, намечаются организационно-технические мероприятия по устранению потерь и использованию резервов рабочего времени. Так, при прокладке минерализованной полосы имеют место потери рабочего времени, связанные с работой, не предусмотренной заданием.

На основе анализа фактического баланса времени и намеченных мер проектировали нормальный баланс времени рабочего дня. В таблице 3 он показан в минутах и процентах (гр. 8-9).

При нормировании проектируют 8-часовой рабочий день, равный 480 мин (100\%). В проектируемый баланс времени рабочего дня (смены) должны входить элементы, необходимые для выполнения установленного технологического про- цесса, то есть время оперативной работы, подготовительно-заключительной работы, обслуживания рабочего места, а также время на отдых и личные надобности.

Расходы времени на работу, не предусмотренную производственным заданием (случайную и др.), на нерегламентируемые перерывы (из-за нарушения трудовой дисциплины, по организационным, техническим и метеорологическим причинам) в норму времени не включают и в нормальный баланс времени рабочего дня не проектируют.

Более эффективное использование рабочего времени, расходуемого на оперативную работу, определяется после обработки хронометражных наблюдений посредством сравнения фактических и улучшенных затрат оперативного рабочего времени на единицу работы.Хронометраж трудовых ресурсов предназначен для измерения затрат времени на выполнение периодически повторяющихся трудовых приемов в процессе оперативной работы. Хронометраж и фотография рабочего времени взаимно дополняют друг друга.

Для каждого хронометражного ряда определятся фактические и улучшенные данные о сумме продолжительности всех замеров, число замеров и средняя арифметическая длительность одного замера. На основе этих данных и данных фактического и проектируемого баланса рабочего времени, определяют нормы времени, нормы выработки и показатели использования рабочего времени (табл. 4). После того, как по каждому хронометражному ряду определена среднеарифметическая величина затрат оперативного рабочего времени (табл. 5), проверяют доброкачественность данных наблюдений и научную обоснованность и достоверность полученных показателей.

Таблица 1

Фотография рабочего времени (прокладка минерализованной полосы в 2 прохода (ДТ-75))

\begin{tabular}{|c|c|c|c|c|}
\hline \multirow[b]{2}{*}{ Наименование элементов работы и перерывов } & \multirow{2}{*}{$\begin{array}{l}\text { № эле- } \\
\text { ментов }\end{array}$} & \multirow{2}{*}{$\begin{array}{l}\text { Текущее } \\
\text { время, } \\
\text { чч:мм:сс }\end{array}$} & \multicolumn{2}{|c|}{ Продолжительность } \\
\hline & & & чЧ:мм:сс & $\begin{array}{c}\text { в мин. с точно- } \\
\text { стью до } 0,1\end{array}$ \\
\hline Начало работы & & $7: 59: 30$ & & \\
\hline Получение задания & 1 & $7: 59: 30$ & $0: 10: 16$ & 10,3 \\
\hline Заправка ГСМ & 2 & 8:09:46 & 0:06:05 & 6,1 \\
\hline Долив воды в радиатор & 3 & $8: 15: 51$ & 0:04:07 & 4,1 \\
\hline
\end{tabular}




\section{Менеджмент. Экономика. Организация}

\begin{tabular}{|c|c|c|c|c|}
\hline Подготовка орудий к работе & 4 & $8: 19: 58$ & 0:09:57 & 10,0 \\
\hline Пуск и прогрев двигателя & 5 & $8: 29: 55$ & $0: 04: 18$ & 4,3 \\
\hline Прокладка минерализованной полосы в 2 прохода & 6 & $8: 34: 13$ & $0: 49: 42$ & 49,7 \\
\hline Очистка рабочих органов плуга & 7 & $9: 23: 55$ & $0: 01: 26$ & 1,4 \\
\hline Отдых и личные надобности & 8 & $9: 25: 21$ & $0: 03: 12$ & 3,2 \\
\hline Прокладка минерализованной полосы в 2 прохода & 6 & $9: 28: 33$ & $0: 52: 11$ & 52,2 \\
\hline Очистка рабочих органов плуга & 7 & $10: 20: 44$ & $0: 01: 35$ & 1,6 \\
\hline Отдых и личные надобности & 8 & $10: 22: 19$ & 0:03:12 & 3,2 \\
\hline Прокладка минерализованной полосы в 2 прохода & 6 & $10: 25: 31$ & $0: 47: 30$ & 47,5 \\
\hline Очистка рабочих органов плуга & 7 & 11:13:01 & $0: 01: 35$ & 1,6 \\
\hline Отдых и личные надобности & 8 & $11: 14: 36$ & 0:03:12 & 3,2 \\
\hline Прокладка минерализованной полосы в 2 прохода & 6 & $11: 17: 48$ & $0: 51: 33$ & $\overline{51,6}$ \\
\hline Очистка рабочих органов плуга & 7 & 12:09:21 & $0: 01: 17$ & 1,3 \\
\hline Обеденный перерыв & 9 & $12: 10: 38$ & 1:00:29 & 60,5 \\
\hline Дозаправка ГСМ & 10 & $13: 11: 07$ & 0:04:04 & 4,1 \\
\hline Уборка препятствий на пути & 11 & $13: 15: 11$ & 0:03:07 & 3,1 \\
\hline Прокладка минерализованной полосы в 2 прохода & 6 & $13: 18: 18$ & $0: 51: 26$ & 51,4 \\
\hline Очистка рабочих органов плуга & 7 & $14: 09: 44$ & $0: 01: 26$ & 1,4 \\
\hline Отдых и личные надобности & 8 & $14: 11: 10$ & $0: 03: 11$ & 3,2 \\
\hline Прокладка минерализованной полосы в 2 прохода & 6 & $14: 14: 21$ & $0: 44: 44$ & 44,7 \\
\hline Очистка рабочих органов плуга & 7 & 14:59:05 & 0:01:17 & 1,3 \\
\hline Отдых и личные надобности & 8 & $15: 00: 22$ & 0:03:18 & 3,3 \\
\hline Прокладка минерализованной полосы в 2 прохода & 6 & $15: 03: 40$ & $0: 52: 15$ & 52,3 \\
\hline Очистка рабочих органов плуга & 7 & $15: 55: 55$ & 0:01:34 & 1,6 \\
\hline Отдых и личные надобности & 8 & $15: 57: 29$ & 0:03:15 & 3,3 \\
\hline Прокладка минерализованной полосы в 2 прохода & 6 & 16:00:44 & $0: 51: 10$ & 51,2 \\
\hline Очистка рабочих органов плуга & 7 & $16: 51: 54$ & 0:01:22 & 1,4 \\
\hline Сдача работы & 12 & $16: 53: 16$ & 0:09:39 & 9,7 \\
\hline Окончание работы & & 17:02:55 & & \\
\hline Итого: & & & & 543,8 \\
\hline
\end{tabular}

Таблица 2

Сводка затрат рабочего времени по элементам

\begin{tabular}{|c|c|c|c|c|}
\hline \multirow[t]{2}{*}{ Наименование элементов работы и перерывов } & \multirow{2}{*}{$\begin{array}{c}\text { Номера } \\
\text { (индексы) } \\
\text { элементов }\end{array}$} & \multicolumn{3}{|c|}{$\begin{array}{l}\text { Сумма продолжительности элементов (в мин) за } \\
\text { день наблюдений }\end{array}$} \\
\hline & & 1 день & 2 день & 3 день \\
\hline Получение задания & 1 & 10,3 & 10,1 & 9,8 \\
\hline Заправка ГСМ & 2 & 6,1 & 6,3 & 6,4 \\
\hline Долив воды в радиатор & 3 & 4,1 & 4,1 & 4,1 \\
\hline Подготовка орудий к работе & 4 & 10,0 & 9,5 & 10,0 \\
\hline Пуск и прогрев двигателя & 5 & 4,3 & 4,9 & 4,6 \\
\hline Прокладка минерализованной полосы в 2 прохода & 6 & 400,6 & 404,0 & 402,0 \\
\hline Очистка рабочих органов плуга & 7 & 11,6 & 11,8 & 11,8 \\
\hline
\end{tabular}


Менеджмент. Экономика. Организация

\begin{tabular}{|c|c|c|c|c|}
\hline Отдых и личные надобности & 8 & 19,4 & 20,0 & 20,2 \\
\hline Дозаправка ГСМ & 10 & 4,1 & 4,0 & 3,8 \\
\hline Уборка препятствий на пути & 11 & 3,1 & 1,2 & 2,8 \\
\hline Сдача работы & 12 & 9,7 & 9,3 & 9,4 \\
\hline ИТОГО: & & 483,3 & 485,2 & 484,9 \\
\hline Обеденный перерыв & 9 & 60,5 & 59,9 & 61,2 \\
\hline Общая продолжительность наблюдений & & 543,8 & 545,1 & 546,1 \\
\hline
\end{tabular}

Таблица 3

Фактический и проектируемый баланс времени рабочего времени

\begin{tabular}{|c|c|c|c|c|c|c|c|c|c|c|}
\hline \multirow{2}{*}{\multicolumn{3}{|c|}{ Классификация затрат 1}} & \multicolumn{3}{|c|}{ Дата наблюдений } & \multicolumn{3}{|c|}{ Фактический баланс } & \multicolumn{2}{|c|}{$\begin{array}{c}\text { Проектируемый } \\
\text { баланс }\end{array}$} \\
\hline & & & & & & сумма за все & в сред. за & & одного & 0 \\
\hline \multirow{10}{*}{ 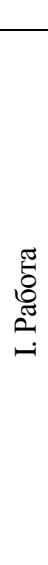 } & & 1 & 2 & 3 & 4 & 5 & 6 & 7 & 8 & 9 \\
\hline & \multirow{4}{*}{$\begin{array}{l}\text { 1) предусмотренная } \\
\text { заданием }\end{array}$} & а)оперативная & 400,6 & 404,0 & 402,0 & 1206,6 & 402,2 & 83,02 & 400,0 & 83,33 \\
\hline & & $\begin{array}{l}\text { б)подготовительно- } \\
\text { заключительная }\end{array}$ & 38,6 & 38,7 & 38,1 & 115,4 & 38,5 & 7,94 & 38,5 & 8,02 \\
\hline & & в)обслуживание рабочего & & & & & & & & \\
\hline & & $\begin{array}{l}\text { места, машины, меха- } \\
\text { низмов }\end{array}$ & 21,6 & 21,3 & 21,8 & 64,7 & 21,6 & 4,45 & 21,5 & 4,48 \\
\hline & \multicolumn{2}{|c|}{ Итого работа, предусмотренная заданием: } & 460,8 & 464,0 & 461,9 & 1386,7 & 462,2 & 95,41 & 460,0 & 95,83 \\
\hline & \multirow{3}{*}{$\begin{array}{l}\text { 2) не предусмот- } \\
\text { ренная заданием }\end{array}$} & $\begin{array}{l}\text { а)поорганизационным } \\
\text { причинам }\end{array}$ & & & & & & & & \\
\hline & & $\begin{array}{l}\text { б)потехническим итехно- } \\
\text { логическим причинам }\end{array}$ & 3,1 & 1,2 & 2,8 & 7,1 & 2,4 & 0,49 & & \\
\hline & & $\begin{array}{l}\text { в)из-занарушения трудо- } \\
\text { вой дисциплины }\end{array}$ & & & & & & & & \\
\hline & \multicolumn{2}{|c|}{ Итого работа, непредусмотренная заданием: } & 3,1 & 1,2 & 2,8 & 7,1 & 2,4 & 0,49 & & \\
\hline \multicolumn{3}{|c|}{ ВСЕГО поразделуІ } & 463,9 & 465,2 & 464,7 & 1393,8 & 464,6 & 95,90 & 460,0 & 95,83 \\
\hline \multirow{8}{*}{ 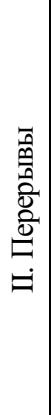 } & \multirow{3}{*}{$\begin{array}{l}\text { 1) регламентируе- } \\
\text { мые }\end{array}$} & $\begin{array}{l}\text { a) отдых иличные надоб- } \\
\text { ности }\end{array}$ & 19,4 & 20,0 & 20,2 & 59,6 & 19,9 & 4,10 & 20,0 & 4,17 \\
\hline & & б)технологические & & & & & & & & \\
\hline & & в) организационные & & & & & & & & \\
\hline & \multicolumn{2}{|c|}{ ИТОГО перерывы регламентируемые: } & 19,4 & 20,0 & 20,2 & 59,6 & 19,9 & 4,10 & 20,0 & 4,17 \\
\hline & \multirow{3}{*}{$\begin{array}{l}\text { 2) нерегламентиру- } \\
\text { емые }\end{array}$} & $\begin{array}{l}\text { a)поорганизационным } \\
\text { причинам }\end{array}$ & & & & & & & & \\
\hline & & $\begin{array}{l}\begin{array}{l}\text { б)из-занарушения трудо- } \\
\text { вой дисциплины }\end{array} \\
\end{array}$ & & & & & & & & \\
\hline & & в)метеорологические & & & & & & & & \\
\hline & \multicolumn{2}{|c|}{ ИТОГО перерывы нерегламентируемые: } & & & & & & & & \\
\hline \multicolumn{3}{|c|}{ ВСЕГО поразделу II } & 19,4 & 20,0 & 20,2 & 59,6 & 19,9 & 4,10 & 20,0 & 4,17 \\
\hline \multicolumn{3}{|c|}{ ВСЕГО поразДеЛам I, II } & 483,3 & 485,2 & 484,9 & 1453,4 & 484,5 & 100,00 & 480,0 & 100,00 \\
\hline
\end{tabular}

Таблица 4

Расчеты нормы времени, нормы выработки и показателей использования рабочего времени

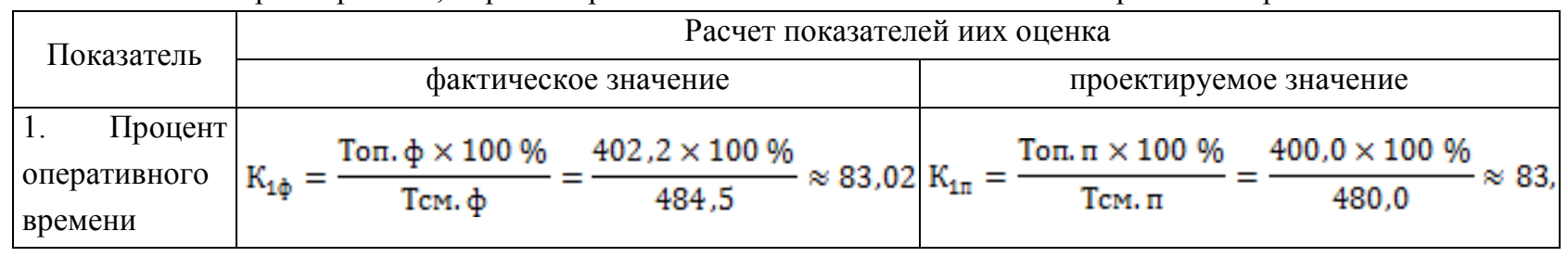




\begin{tabular}{|c|c|c|}
\hline $\begin{array}{l}\text { 2. Норма вре- } \\
\text { мени на еди- } \\
\text { ницу продук- } \\
\text { ции (работ), } \\
\text { мин. }\end{array}$ & $\mathrm{H}_{\mathrm{pp} 1 \emptyset}=44,53$ & $\mathrm{H}_{\mathrm{Bp} 1 \mathrm{~m}}=44,53$ \\
\hline $\begin{array}{l}\text { 3. Норма вы- } \\
\text { работки, км }\end{array}$ & $\mathrm{H}_{\mathrm{gup} 1 \phi}=\frac{\text { Топ. } \Phi}{\mathrm{H}_{\mathrm{Bp} 1 \Phi}}=\frac{402,2}{44,53} \approx 9,03$ & $\mathrm{H}_{\mathrm{Bup} 1 \mathrm{~m}}=\frac{\text { Toп, } \mathrm{I}}{\mathrm{H}_{\mathrm{Bp} 1 \mathrm{~m}}}=\frac{400,0}{44,53} \approx 8,98$ \\
\hline
\end{tabular}

Таблица 5

Расчет величин ошибки арифметической середины для хронометражного ряда элемента «Прокладка минерализованной полосы в 2 прохода»

\begin{tabular}{|c|c|c|c|c|}
\hline Варианты & Частоты & $\begin{array}{c}\text { Арифметическая } \\
\text { середина } M_{\mathrm{cp}}\end{array}$ & Отклонение $a$ & $a^{2}$ \\
\hline 3,9 & 1 & \multirow{12}{*}{4,5} & $-0,6$ & 0,36 \\
\hline 4,0 & 1 & & $-0,5$ & 0,25 \\
\hline 4,1 & 2 & & $-0,4$ & 0,16 \\
\hline 4,2 & 3 & & $-0,3$ & 0,09 \\
\hline 4,3 & 3 & & $-0,2$ & 0,04 \\
\hline 4,4 & 4 & & $-0,1$ & 0,01 \\
\hline 4,5 & 6 & & 0,0 & 0,00 \\
\hline 4,6 & 3 & & 0,1 & 0,01 \\
\hline 4,7 & 3 & & 0,2 & 0,04 \\
\hline 4,8 & 2 & & 0,3 & 0,09 \\
\hline 4,9 & 1 & & 0,4 & 0,16 \\
\hline 5,0 & 1 & & 0,5 & 0,25 \\
\hline & & & Итого: & 2,10 \\
\hline
\end{tabular}

С этой целью определяют коэффициент устойчивости хроноряда и среднюю ошибку (точность) проведенных наблюдений (табл. 6).

Хроноряд считается доброкачественным, если величина средней ошибки не превышает 5-10 \%.

По данным расчетов, проведенных в табл. 6 , установили, что хронометражный ряд является доброкачественным.

Типовые нормы выработки на прокладку минерализованной полосы, выполняемые в горных условиях, содержат следующие разделы:
1. Содержание работы: получение задания, подготовка тракторного агрегата к работе (заправка, долив воды в радиатор, подготовка орудий к работе, пуск и прогрев двигателя), прокладка минерализованных противопожарных полос, обслуживание агрегата в течение смены (очистка рабочих органов орудий от налипшей почвы, дозаправка трактора топливом и водой, регулировка рабочих органов), сдача и приемка выполненной работы.

Таблица 6

Расчет показателей доброкачественности хронометражных рядов

\begin{tabular}{|l|c|c|c|}
\hline \multicolumn{1}{|c|}{ Показатель } & Расчетная формула & $\begin{array}{c}\text { Прокладка минерализованной } \\
\text { полосы в 2 прохода }\end{array}$ & Нормат. знач. \\
\hline $\begin{array}{l}\text { 1. Коэффициент устойчивости } \\
\text { хроноряда (Ку) }\end{array}$ & $\mathrm{Ky}=\frac{t_{\max }}{t_{\min }}$ & $\frac{5,0}{3,9} \approx 1,28$ & $<3,0$ \\
\hline
\end{tabular}




\begin{tabular}{|l|c|l|c|}
\hline $\begin{array}{l}\text { 2. Показатели достоверности хро- } \\
\text { норяда: } \\
- \text { среднеквадратическое отклоне- } \\
\text { ние } \sigma\end{array}$ & $\sigma= \pm \frac{\sqrt{2 a^{2}}}{n-1}$ & $\pm \frac{\sqrt{2,10}}{30-1} \approx \pm 0,005$ & \\
\hline - средняя ошибка $m$ & $m=\frac{ \pm \sigma}{\sqrt{n}}$ & $\frac{ \pm 0,005}{\sqrt{30}} \approx \pm 0,009$ & - \\
\hline $\begin{array}{l}\text { 3. Выводы о доброкачественности } \\
\text { хроноряда }(P)\end{array}$ & $P=\frac{m \times 100 \%}{M_{\text {ср }}}$ & $\frac{0,009 \times 100 \%}{4,5} \approx 0,20 \%$ & $<5 \%$ \\
\hline
\end{tabular}

2. Исполнитель: тракторист-машинист.

3. Тарифный разряд при работе на тракторе ДТ-75: 5-й.

Норма выработки на прокладку минерализованной полосы в 2 прохода при крутизне склона до 20 град представлена в табл. 7.

Таблица 7

Нормы выработки на прокладку минерализованной полосы в 2 прохода при крутизне склона до 20 град

\begin{tabular}{|c|c|}
\hline $\begin{array}{c}\text { Тип трактора, состав } \\
\text { агрегата }\end{array}$ & $\begin{array}{c}\text { Норма выработки, км } \\
\text { при слабой каменистости } \\
\text { почвы }\end{array}$ \\
\hline $\begin{array}{c}\text { Гусеничный, ДТ-75 в } \\
\text { агрегате с плугом }\end{array}$ & 8,98 \\
\hline
\end{tabular}

Таким образом, на сегодняшний день в лесном хозяйстве отсутствуют актуализированные нормы выработки и нормы времени, а действующая методика распределения субвенций не учитывает территориальные особенности ведения лесного хозяйства, опираясь на устаревшие нормативы.

Следует отметить, что модернизация устаревших норм времени и норм выработки в лесном хозяйстве необходима по ряду причин:

- во-первых, использование устаревших нормативов влечет за собой искажение плановых заданий и является тормозом на пути развития новых технологий и внедрения инноваций;

-во-вторых, при определении нормативных затрат по видам лесохозяйственных работ на основе устаревших нормативов, неизбежны ошибки, приводя- щие в дальнейшем к занижению или завышению объемов финансирования работ;

- в-третьих, существует объективная необходимость в нормировании работ, осуществляемых на базе новой техники или технологий.

В лесном хозяйстве в связи с широкой механизацией трудовых процессов техническое нормирование становится основным научным методом изучения резервов рабочего времени.

Лесное хозяйство - специфичная отрасль ввиду наличия особенностей, таких как длительный производственный цикл, связь с природно-климатическими условиями, значительная географическая рассредоточенность предметов труда, выраженная сезонность и трудоемкость работ, высокий уровень рисков лесохозяйственных работ. Это означает, что механически перенести существующие в других отраслях принципы, методы и приемы организации производства и его финансирования на лесное хозяйство невозможно, что усиливает важность решения задачи нормирования процессов и операций лесохозяйственного производства. В этой связи необходима разработка типовых норм выработки и норм времени с учетом научноисследовательских разработок, современных технологий работ и новейшей техники на региональнотипологической основе.

\section{Библиографический список}

1. Rational use of Forest as a renewable natural resourse / Yu. N. Stepanova, Zinoveva I.S., Bezrukova T.L., Kuksova I.V. // European Research Studies Journal. - 2018. - T.21. - № S1. - C. 443-454 
2. Function value analysis in Forestry practice / S. S. Morkovina, V. K. Rezanov, E. A. Panyavina, V. E. Sukhova // Innovation Management and Education Excellence through Vision 2020. Proceedings of the 31st International Business Information Management Association Conference (IBIMA).- 2018. - C. 4419-4425.

3. Козлова, О. Г. Оценка результативности управленческой деятельности органов исполнительной власти субъектов РФ в области лесных отношений / О. Г. Козлова, И. А. Авдеева // Актуальные направления научных исследований XXI века: теория и практика. - 2018. - Т.6. - № 2(38). - С. 307-311

4. Петров, А. П. Рыночная организация лесного хозяйства: опыт зарубежных стран и российских регионов / А. П. Петров, С. С. Морковина // Лесотехнический журнал. - 2016. - Т. 6. - № 4(24). - С. 250-258

5. Морковина, С. С. Экономические аспекты развития предпринимательства в лесном хозяйстве малолесной зоны / С. С. Морковина, Е. А. Панявина, Д. А. Панасенко //Социально-экономические явления и процессы. - 2016. - Т.11. - № 8. - С. 58-65

6. Морковина, С. С. Государственно-частное партнерство в лесном хозяйстве ЦЧР: формы реализации и перспективы / С. С. Морковина, Б. Шанянь, О. И. Драпалюк // Лесотехнический журнал. - 2013. - № 2(10). C. $179-189$.

7. Постановление Правительства РФ «Об утверждении Методики распределения между субъектами Российской Федерации субвенций из федерального бюджета для осуществления отдельных полномочий Российской Федерации в области лесных отношений, реализация которых передана органам государственной власти субъектов Российской Федерации»[Электронный ресурс] :от 29.12.2006 г. № 838 (ред. от 13.02.2019 г.)// КонсультантПлюс онлайн - Некоммерческие интернет-версии системы Консультант-Плюс. - Режим доступа: http://www.consultant.ru/document/cons_doc_LAW_107227/

8. Приказ Рослесхоза «Об утверждении Порядка определения нормативных затрат на выполнение работ федеральными бюджетными и автономными учреждениями, в отношении которых Федеральное агентство лесного хозяйства осуществляет функции и полномочия учредителя»[Электронный ресурс] :от 02.03.2017 № 81// КонсультантПлюс онлайн - Некоммерческие интернет-версии системы Консультант-Плюс. - Режим доступа: http://www.consultant.ru/document/cons_doc_LAW_216526/

9. Морковина, С. С. Финансовый механизм поддержки инноваций в лесном хозяйстве / С. С. Морковина, И. В. Сибиряткина, А. В. Иванова // Лесотехнический журнал. - 2016. - Т.6. - № 3(23). - С. 221-231

10. Постановление Госкомтруда СССР, Президиума ВЦСПС «Об утверждении Положения об организации нормирования труда в народном хозяйстве» [Электронный ресурс]: от 19.06.1986 N 226/П-6 // КонсультантПлюс онлайн - Некоммерческие интернет-версии системы Консультант-Плюс. - Режим доступа: http://www.consultant.ru/cons/cgi/online.cgi?from=4420-32\&rnd=D6DE0FEACA172B5EDD2C77B70952C6AA $\&$ req $=$ doc $\&$ base $=$ ESU $\& n=27618 \&$ REFDOC $=4420 \&$ REFBASE $=$ ESU\#47n3mvzz99k

11. Справочник по тарификации механизированных и ручных работ в сельском, водном и лесном хозяйстве [Электронный ресурс]: утв. Постановлением Госкомтруда СССР, ВЦСПС от 03.11.1986 N 462/26-62// КонсультантПлюс онлайн - Некоммерческие интернет-версии системы Консультант-Плюс. - Режим доступа: http://www.consultant.ru/document/cons_doc_LAW_156154/

12. Бычин, В. Б. Нормирование труда : учеб. / В. Б. Бычин, С. В. Малинин, Е. В. Новикова. М.: ИНФРА-М, 2017. - 348 c.

\section{References}

1. Stepanova Yu. N., Zinoveva I.S., Bezrukova T.L., Kuksova I.V. Rational use of Forest as a renewable natural resourse // European Research Studies Journal. - 2018. - T.21. - № S1. - C. 443-454

2. Morkovina S. S., Rezanov V. K., Panyavina E. A., Sukhova V. E. Function value analysis in Forestry practice // Innovation Management and Education Excellence through Vision 2020. Proceedings of the 31st International Business Information Management Association Conference (IBIMA).- 2018. - C. 4419-4425. 
3. Kozlova O. G., Avdeeva I. A. Evaluation of the effectiveness of management activities of the executive authorities of the constituent entities of the Russian Federation in the field of forest relations // Actual areas of research of the XXI century: theory and practice. 2018. -T.6. № 2 (38). p. 307-311

4. Petrov A. P. Carrot S. S. Market Organization of Forestry: Experience of Foreign Countries and Russian Regions // Forest Engineering Journal. - 2016. - T.6.- № 4 (24). - p. 250-258

5. Morkovina S. S., Paniavina E. A., Panasenko D. A. Economic aspects of the development of entrepreneurship in the forestry of the low forest zone // Socio-economic phenomena and processes. 2016. T.11. № 8. p. 58-65.

6. Morkovina S. S., Shanyan B., Drapalyuk O. I. Public-Private Partnership in the Forestry of the Central Chernozem Region: Forms of Implementation and Prospects // Forestry log. 2013. № 2 (10). p. 179-189

7. Decree of the Government of the Russian Federation "On Approval of the Method of Distribution between Subjects of the Russian Federation of Subventions from the Federal Budget for the Implementation of Certain Powers of the Russian Federation in the Field of Forest Relations, the implementation of which has been transferred to state authorities of the subjects of the Russian Federation" [Electronic resource]: No. 838 of December 29,2006 (Ed. 13.02.2019) // Kon-sultantPlyus online - Non-commercial Internet versions of the system Consultant Plus. Access mode: http://www.consultant.ru/document/cons_doc_LAW_107227/

8. The Order of the Rosleskhoz "On Approval of the Procedure for Determining the Standard Expenditures for the Execution of Works by Federal Budget and Autonomous Institutions for which the Federal Agency for Forestry performs the functions and powers of the founder" [Electronic resource]: No. 81 dated 03.03.2017 // ConsultantPlus online - Non-profit Internet version of Consultant Plus. Access mode: http://www.consultant.ru/document/cons_doc_LAW_216526/

9. Morkovina, S.S. Financial mechanism to support innovation in forestry [Text] / S.S. Morkovina, I. V. Sibiryatkina, A. V. Ivanova // Forest-technical journal. 2016. T.6. № 3 (23). pp. 221-231

10. Resolution of the USSR State Labor Committee, Presidium of the All-Union Central Council of Trade Unions on the approval of the regulation on the organization of labor valuation in the national economy [Electronic resource]: от 19.06.1986 N 226/П-6 // ConsultantPlus online - Non-profit Internet version of Consultant Plus. Access mode:http://www.consultant.ru/cons/cgi/online.cgi?from=442032\&rnd=D6DE0FEACA172B5EDD2C77B70952C6AA $\&$ req $=$ doc \&base $=$ ESU $\& \mathrm{n}=27618 \&$ REFDOC $=4420 \&$ REFBASE $=$ ESU\#47n3mvzz99k

11. Handbook of pricing mechanized and manual work in agriculture, water and forestry approved. By decree of the USSR State Labor Committee, the All-Union Central Council of Trade Unions[Electronic resource]: от 03.11.1986 N 462/26-62// ConsultantPlus online - Non-profit Internet version of Consultant Plus. Access mode:http://www.consultant.ru/document/cons_doc_LAW_156154/

12. Bychin V. B., Malinin S. V., Novikova E. V. Labor Rationing : textbook. M. : INFRA-M, 2017. 348 p.

\section{Сведения об авторах}

Морковина Светлана Сергеевна- профессор кафедры менеджмента и экономики предпринимательства ФГБОУ ВО «Воронежский государственный лесотехнический университет имени Г.Ф. Морозова», доктор экономических наук, профессор, г. Воронеж, Российская Федерация; e-mail: tc-sveta@mail.ru.

Панявина Екатерина Анатольевна - доцент кафедры менеджмента и экономики предпринимательства ФГБОУ ВО «Воронежский государственный лесотехнический университет имени Г.Ф. Морозова», кандидат экономических наук, г. Воронеж, Российская Федерация; e-mail: panyavina-e-a @ mail.ru.

Авдеева Ирина Александровна - доцент кафедры менеджмента и экономики предпринимательстваФГБОУ ВО «Воронежский государственный лесотехнический университет имени Г.Ф. Морозова», кандидат сельскохозяйственных наук, г. Воронеж, Российская Федерация; e-mail: ia240777@mail.ru.

\section{Information about authors}

Morkovina Svetlana Sergeevna-Professor of Department of management and Economics entrepreneurship, Federal State Budget Education Institution of Higher Education «Voronezh State University of Forestry and Technologies 
named after G.F. Morozov», DSc (Economics), Professor, Voronezh, Russian Federation; e-mail: tc-sveta@mail.ru.

Panyavina Ekaterina Anatolievna- Associate Professor of Department of management and Economics entrepreneurship, Federal State Budget Education Institution of Higher Education «Voronezh State University of Forestry and Technologies named after G.F. Morozov», PhD (Economics), Voronezh, Russian Federation; e-mail: panyavina-e-a@mail.ru.

Avdeeva Irina Aleksandrovna - Associate Professor of Department of management and Economics entrepreneurship, Federal State Budget Education Institution of Higher Education «Voronezh State University of Forestry and Technologies named after G.F. Morozov», PhD. (Agriculture), Voronezh, Russian Federation; e-mail: ia240777@mail.ru

DOI: $10.12737 /$ article_5c92017294e4b5.84748067

УДК 647.6

ЭКОЛОГО-ЭКОНОМИЧЕСКИЕ ПРИОРИТЕТЫ РАЗДЕЛЬНОГО СБОРА ОТХОДОВ кандидат социологических наук, старший преподаватель Е.А. Преликова ${ }^{1}$

кандидат технических наук, доцент, заведующий кафедрой охраны труда и окружающей среды

\section{В.В. Юшин ${ }^{1}$}

доктор экономических наук, профессор, зав. кафедрой региональной экономики и менеджмента

Ю.В. Вертакова ${ }^{1}$

1 - ФГБОУ ВО «Юго-Западный государственный университет», Курск, Российская Федерация

В статье рассмотрены преимущества раздельного сбора отходов как наиболее оптимальной схемы обращения с ТКО. Опыт зарубежных стран показывает, что использование отходов, разделение их на полезные компоненты, применяемые в качестве вторичного сырья на предприятиях, позволяют не только извлекать финансовую выгоду из мусора, но и очищать окружающую среду. Целью исследования является выявление эколого-экономические приоритеты раздельного сбора отходов. В исследовании использованы теоретические и эмпирические методы, в частности: обзор литературы, логический и системный анализ, методы сбора эмпирических данных, описания, прогноза и обработки результатов исследования. Нормативно-правовая база в сфере обращения с отходами РФ претерпела значительные изменения. Появились законы, указы президента, проекты, направленные на решение проблемы по раздельному сбору отходов. Государством разработан ряд мер, предусматривающих деятельность региональных операторов, механизмов управления, обеспечивающих использование мусора в качестве сырья, вовлекаемого в производство продукции. Есть надежда, что такие меры оправдают себя, и переход к раздельному сбору отходов останется не на бумагах, а в реальной жизни. Для достижения цели исследования авторами был проанализирован международный опыт решения подобных проблем, нормативно-правовое обеспечение проблемы обращения с отходами, выявлены и обоснованы экономические приоритеты, а также рассмотрена практика раздельного сбора отходов и деятельность регионального оператора ТКО в Курской области. Результатом исследования стал анализ перспективных направлений раздельного сбора мусора, представлены эколого-экономические приоритеты и мотивация перехода на раздельный сбор отходов.

Ключевые слова: отходы, утилизация, раздельный сбор, вторичное сырье, рециклинг, сертификация, региональный оператор.

\section{ENVIRONMENTAL AND ECONOMIC PRIORITIES OF SEPARATE WASTE COLLECTION}

Candidate of sociological sciences, senior lecturer, E.A. Prelikova ${ }^{1}$

Candidate of engineering science, senior lecturer, head of department of labor and environmental protection 